\title{
PRÁTICAS DOCENTES NO ENSINO SUPERIOR: RELATO DE EXPERIÊNCIA EM ESTÁGIO DE DOCÊNCIA ${ }^{1}$
}

\section{TEACHING EXPERIENCES IN UNIVERSITY EDUCATION: REPORT OF AN EXPERIENCE IN TEACHING PRACTICE}

\author{
Adriana Silva Barbosa ${ }^{1}$, Licia Marques Vidal ${ }^{2}$ Ana Cristina Santos Duarte ${ }^{3}$, Eduardo \\ Nagib Boery ${ }^{4}$, Rita Narriman Silva de Oliveira Boery ${ }^{4}$ Zenilda Nogueira Sales ${ }^{4}$ \\ 1,2,3,4 Programa de Pós-Graduação em Enfermagem e Saúde da UESB \\ ${ }^{1}$ Comitê de Ética em Pesquisa da UESB drybarbosa@ yahoo.com.br. \\ ${ }^{2}$ Departamento de Ciências Naturais (DCN) da UESB. liciavidal@hotmail.com. \\ ${ }^{3}$ Departamento de Ciências Biológicas (DCB) da UESB tinaduarte2@ gmail.com. \\ ${ }^{4}$ Departamento de Saúde da UESB eboery@ig.com.br, rboery@gmail.com, zenysalles@gmail.com
}

\section{Resumo}

O processo ensino-aprendizagem possui especial relevância no ensino superior, devendo configurar-se como uma relação dinâmica e dialógica, já que a universidade tem papel de destaque na formação do profissional requerido pela sociedade contemporânea. $\mathrm{O}$ objetivo deste trabalho é relatar uma experiência pedagógica bem sucedida de duas mestrandas, descrevendo as atividades das mesmas na disciplina Estágio de Docência, do Programa de Pós-Graduação em Enfermagem e Saúde, da Universidade Estadual do Sudoeste da Bahia, analisando à luz da literatura os desafios inerentes à prática docente no ensino superior em Saúde. Todas as atividades desenvolvidas significaram uma oportunidade de crescimento e troca de saberes e experiências, favorecendo a aquisição de conhecimentos por todos os envolvidos neste processo: discentes de três cursos de graduação distintos (Enfermagem, Medicina e Odontologia), os docentes e as mestrandas.

Palavras - Chave: aprendizagem, ensino, ensino superior, universidade, Saúde.

\begin{abstract}
The teaching-learning process has a special relevancy in university education, and thus, ought to be configured as a dynamic-dialogic relation, since the university has a prominent role in the formation of the professionals required by contemporaneous society. The aim of this work is to report the successful pedagogical experience of two Master Degree students, describing their activities in the subject Teaching Practice, of the Postgraduate Program of Nursing and Healthcare Studies, of the Universidade Estadual do Sudoeste da Bahia (State University of the Southeast of Bahia), analyzing the light of literature the inherent challenges of teaching practice in healthcare university education. All the developed activities promoted growth opportunity and knowledge and experience exchange, enhancing the acquisition of knowledge by all people involved in this process: students of three different graduate courses (Nursing, Medicine and Dentistry), the teachers and the Master Degree students.
\end{abstract}

Keywords: learning, teaching, higher education, university, Health.

\footnotetext{
${ }^{1}$ Relato de Experiência elaborado nas disciplinas Estágio de Docência e Processo Ensino-Aprendizagem em Ciências da Saúde do Programa de Pós-Graduação em Enfermagem e Saúde, em nível de Mestrado Acadêmico, da Universidade Estadual do Sudoeste da Bahia (UESB).
} 


\section{Introdução}

Este estudo é um relato de experiência de duas mestrandas, uma bióloga e uma enfermeira, do Programa de Pós-Graduação em Enfermagem e Saúde (PPGES), em nível de Mestrado Acadêmico e de caráter interdisciplinar, da Universidade Estadual do Sudoeste da Bahia (UESB), campusde Jequié, na disciplina Estágio de Docência, tendo como suporte as disciplinas Processo Ensino-aprendizagem em Ciências da Saúde e Metodologia da Pesquisa Científica em Saúde. O estágio foi desenvolvido no segundo semestre de 2009, na UESB, envolvendo atividades inseridas nas disciplinas Deontologia em Enfermagem e Bioética, Módulo Ético-Humanístico I e Bioética e Metodologia da Pesquisa Científica em Saúde, com aulas ministradas nos Cursos de Graduação em Enfermagem ( $2^{\circ}$ semestre), Odontologia ( $3^{\circ}$ semestre) e Medicina $\left(1^{\circ}\right.$ semestre), sob a orientação de dois doutores do referido Programa de Pós-Graduação e responsáveis por estas disciplinas.

O objetivo deste trabalho é relatar essa experiência pedagógica considerada bem sucedida pelos envolvidos no processo, descrevendo as vivências dos mesmos nas atividades propostas no Programa de Pós-Graduação em Enfermagem e Saúde, para o exercício da docência, analisando à luz da literatura os desafios inerentes à prática docente no ensino superior em Saúde.

Assim, para contextualizarmos essa experiência, tornou-se importante lembrar um pouco da história do ensino superior no Brasil com a chegada da família real portuguesa (1808) e, posteriormente, da criação das Escolas de Cirurgia e Anatomia, em Salvador - Bahia, e de Anatomia e Cirurgia e da Academia da Guarda Marinha, ambas no Rio de Janeiro. A criação destas instituições de ensino superior e, dois anos mais tarde, da Academia Real Militar, também no Rio de Janeiro, tinha como finalidade fornecer um diploma de nível superior àqueles que iriam ocupar cargos privilegiados em um mercado de trabalho restrito (MARTINS, 2002).

Nesta perspectiva, o ensino superior desenvolveu-se lentamente no Brasil (MARTINS, 2002), uma vez que a preocupação com este nível de ensino iniciou-se somente no século XIX (SILVA, 2001) e que, até o final desse século, existiam apenas vinte e quatro estabelecimentos de ensino superior neste país, os quais funcionavam como escolas isoladas (SEVERINO, 2008).

As universidades só foram introduzidas a partir da terceira década do século XX, mantendo como características os traços advindos da constituição do ensino superior no 
tempo do Império, tais como o caráter privado de sua dependência administrativa e a natureza isolada das instituições (SEVERINO, 2008). Apesar disso, já no início deste século, foram travados vários debates que apontavam as universidades como instituições que tinham como função abrigar a ciência e os cientistas para promover a pesquisa e formar profissionais a serviço da sociedade (MARTINS, 2002; SILVA, 2001).

Assim, a pesquisa foi introduzida no Brasil na década de 1930 a partir do deslocamento da produção científica do campo para o interior da academia e a organização de espaços de reflexão e produção de trabalhos com o intuito de construir uma escola pública de qualidade. A pesquisa educacional neste país surgiu na mesma época e tem como marcos iniciais a introdução de um serviço de teses no Departamento de Educação do Distrito Federal por Anísio Teixeira, em 1931, e a criação do Instituto Nacional de Estudos Pedagógicos (INEP) em 1938. O desenvolvimento deste tipo de pesquisa pode ser dividido em cinco períodos: $1^{\circ}$ ) 1938 a 1956, $2^{\circ}$ ) de 1956 a 1964, 3º) de 1964 a $1971,4^{\circ}$ ) de 1971 a 1985 e $5^{\circ}$ ) de 1985 até o momento atual (ROSA; LOPES, 2009).

As universidades são consideradas instituições de grande importância, assumindo um relevante papel enquanto instituições formadoras de opinião e geradoras de conhecimento, uma vez que as mesmas devem estar sustentadas em três pilares: ensino, pesquisa e extensão.

Estes três pilares denotam que as pesquisas, realizadas em todas as áreas do conhecimento, devem trazer contribuições à ciência e à sociedade, que a extensão deve garantir o retorno à comunidade - sociedade do conhecimento que é produzido na universidade e que o ensino não deve se restringir à mera transmissão de informações, mas deve atuar no desenvolvimento de uma postura crítico- reflexiva dos discentes para que os mesmos sejam capazes de relacionar teoria e prática de uma forma dinâmica e, desse modo, aplicar e aprimorar os conhecimentos obtidos no âmbito da universidade na realidade em que estão inseridos.

Neste contexto, o processo ensino-aprendizagem assume especial relevância no ensino superior, uma vez que deve se configurar como uma relação dinâmica e dialógica que propicia a socialização, a troca e a transformação dos conhecimentos na relação docente - discente e discente - discente (LOPES, 1996), favorecendo assim a apropriação dos conhecimentos por todos envolvidos neste processo e o preparo dos discentes para as exigências da vida em sociedade e do exercício profissional, de forma 
que os mesmos sejam capazes de refletir e tomar decisões diante das mais diversas situações.

Nesta perspectiva e considerando o papel da universidade na formação do profissional que é requerido pela sociedade contemporânea, em 2009, foi implantado, na UESB o curso de Mestrado Acadêmico do Programa de Pós-Graduação em Enfermagem e Saúde, o qual inseriu no currículo duas disciplinas voltadas para a formação de docentes: Processo Ensino-Aprendizagem em Ciências da Saúde e Estágio de Docência. A primeira, de cunho teórico e carga horária de 30 (trinta) horas, visa a promover a discussão de conteúdos educacionais e estimular a geração de conhecimento inter-relacionando as áreas de educação e de saúde. A segunda, de cunho prático e carga horária também de 30 (trinta) horas, visa a familiarizar o mestrando com a prática docente no ensino superior, a qual envolve também a geração de conhecimento.

Diante da relação de complementaridade inerente às duas disciplinas e inserindo também conhecimentos da disciplina Metodologia da Pesquisa Científica em Saúde, tornou-se relevante elaborar este relato de experiência, docente e discente, na disciplina Estágio de Docência. Para tanto, participamos do planejamento, execução e avaliação das disciplinas: Deontologia em Enfermagem e Bioética, Módulo Ético-Humanístico I e Bioética e Metodologia da Pesquisa Científica em Saúde, que transcorrem de forma integrada nos currículos dos cursos da área de saúde, pertencentes ao Departamento de Saúde da UESB, campus de Jequié.

\section{Vivendo o planejamento na prática docente}

O objetivo da disciplina Estágio de Docência é inserir o profissional de Saúde na prática docente, vivenciando os três pilares da universidade - ensino, pesquisa e extensão -, não apenas cumprindo algumas atividades em sala de aula, mas envolvendoo em projetos de pesquisa e extensão já em andamento, propiciando a vivência extramuros da universidade e o acompanhamento de discentes através de orientações para elaboração de artigos científicos no intuito de desenvolver a prática da pesquisa.

Para que a disciplina transcorresse de forma satisfatória, a etapa planejamento das ações contribuiu decisivamente. O planejamento faz parte da vida do docente e pudemos vivenciar isso. Dele depende a execução das atividades de forma organizada para o alcance dos objetivos propostos. Segundo Gil (2006, p. 95), planejar é “o 
processo sistematizado mediante o qual se pode conferir maior eficiência às atividades educacionais para, em determinado prazo, alcançar as metas estabelecidas".

Planejar exige um conhecimento prévio da realidade que se vai vivenciar. Então, tomamos conhecimento da ementa das disciplinas, das turmas com as quais trabalharíamos, do conteúdo programático, das referências utilizadas e nos organizamos na execução das atividades. Inicialmente, elencamos as aulas que seriam ministradas por nós (inserção no ensino); depois elegemos, dentre os temas a serem abordados em Bioética, aquele com o qual possuíamos mais afinidade para orientação de discentes na elaboração de artigo científico (inserção na pesquisa) e, posteriormente, traçamos as nossas ações em três projetos, simultaneamente de pesquisa e extensão, intitulados " $\mathrm{O}$ despertar para a saúde do homem: a importância da prevenção das afecções prostáticas', "Prevenção do uso e abuso de drogas ilícitas" e "Hipertensão arterial sistêmica e qualidade de vida de motoristas de transporte de carga interestadual" (este último ainda em fase de implantação) (inserção na extensão).

As atividades desenvolvidas foram planejadas juntamente com os orientadores/docentes das disciplinas da graduação Deontologia em Enfermagem e Bioética (curso de Enfermagem), Módulo Ético-Humanístico I e Bioética (curso de Medicina) e Metodologia da Pesquisa Científica em Saúde (cursos de Enfermagem e Odontologia), cenário esse do Estágio de Docência. Os planos de curso das disciplinas já estavam elaborados pelos docentes, tendo em vista que esta atividade é realizada semanas ou até meses antes do início do período letivo, por necessitar de aprovação em departamento. No entanto, com base na prerrogativa da flexibilização do planejamento de ensino, o plano de curso já elaborado foi adaptado para a inserção de atividades/atribuições das mestrandas na prática docente. Além disso, foi elaborado um novo cronograma de atividades, constituindo, desse modo, um aprendizado.

Sabíamos que seria um grande desafio a nossa inserção nessas atividades, uma vez que, à primeira vista, o Estágio de Docência gera ansiedade, dúvidas e insegurança. Não sabíamos ao certo como nos portar enquanto mestrandas/estagiárias, nem exatamente o que deveríamos falar com os discentes, os quais também traziam uma expectativa com relação à nossa participação nas disciplinas. Porém, para nossa satisfação, o processo ocorreu de forma prazerosa e enriquecedora. O crescimento foi gradativo e a convivência mestrandas - discentes - docentes revelou-se como algo fascinante no desenvolvimento e construção das atividades realizadas. Todos os envolvidos participaram da evolução das atividades realizadas e celebraram a 
concretização dos objetivos traçados. Além disso, vale ressaltar que esta experiência também foi nova para os docentes, considerando que foi a primeira vez que a disciplina Estágio de Docência foi oferecida pelo Programa de Pós-Graduação em Enfermagem e Saúde.

Um dos aspectos observados no decorrer das práticas educacionais desenvolvidas é que o exercício da docência requer algumas habilidades do docente que estimulem o discente e favoreçam a concretização do processo ensino-aprendizagem. Como afirma Lopes (1996), o docente deve favorecer situações que estimulem a iniciativa e o diálogo entre o discente e o docente, bem como o diálogo com o saber acumulado historicamente e situações que despertem o interesse dos discentes na apropriação do conhecimento. Buscamos, então, estratégias que fortalecessem a participação dos discentes nas atividades como, por exemplo, a realização de dinâmicas de grupo, trabalhos em equipe, leitura de textos e discussão em sala de aula.

Essas habilidades dizem respeito a saber ouvir e saber se comunicar de forma clara e objetiva, manter-se perante os discentes como um mediador do conhecimento e não como um detentor do saber, além de subsidiar o desenvolvimento de práticas saudáveis em sala de aula, que produzam a construção do conhecimento mediante a segurança em relação ao conteúdo a ser abordado e a humildade no reconhecimento das nossas limitações, enquanto seres em processo de aprendizagem constante. Foram algumas dessas habilidades que buscamos desenvolver ao longo das nossas vivências enquanto participantes desse processo.

Outro aspecto que observamos de grande valia para nossa experiência foi a ruptura nos paradigmas tradicionais que engessaram a formação educacional por muitas décadas no Brasil (nos quais também fomos formadas) e que estão sendo substituídos por práticas inovadoras, inclusivas, libertadoras, nas quais "a relação professor-aluno é horizontal e não imposta" (MIZUKAMI, 1986). Nessa relação, o educador se torna educando e o educando se torna educador para que haja o processo educacional. Estas idéias são inspiradas no educador Paulo Freire e permeiam muitas das práticas no ensino superior na atualidade.

Estagiar/atuar nessa perspectiva chamou-nos a atenção, uma vez que fomos formadas em outra abordagem de educação (abordagem tradicional) e não é tarefa fácil vivenciar novas práticas metodológicas no papel de educadoras, porém esta oportunidade fez-nos refletir quanto à nossa contribuição no processo educativo discente e de como a participação do outro - o educando/discente -, enquanto sujeito de 
sua própria educação, é fundamental para a concretização do processo ensinoaprendizagem.

\section{A execução do plano e das atividades}

\begin{tabular}{|c|c|}
\hline Etapas & Sinopse do plano e cronograma de atividades desenvolvidas \\
\hline $\begin{array}{c}\text { Planejamento das } \\
\text { ações }\end{array}$ & $\begin{array}{l}\text { 1. Reunião com os orientadores/ professores para: } \\
\text { 1.1. Conhecimento dos planos de curso e ementas das disciplinas; } \\
\text { 1.2. Definição das atividades a serem desenvolvidas; } \\
\text { 2. Apresentação das mestrandas às turmas nas seria realizado o } \\
\text { Estágio de Docência. }\end{array}$ \\
\hline $\begin{array}{l}\text { Insersão no } \\
\text { ensino }\end{array}$ & $\begin{array}{l}\text { 1. Escolha das dinâmicas, vídeos e mensagem a serem utilizados } \\
\text { nas aulas; } \\
\text { 2. Elaboração dos planos de aula; } \\
\text { 3. Preparo dos contéudos a serem trabalhado em sala de aula; } \\
\text { 4. Realização das aulas. }\end{array}$ \\
\hline $\begin{array}{l}\text { Insersão na } \\
\text { pesquisa }\end{array}$ & $\begin{array}{l}\text { 1. Escolha dos temas de Bioética a serem empregados na } \\
\text { elaboração de artigos científicos pelas discentes; } \\
\text { 2. Orientações das discentes sobre como pesquisar e elaborar } \\
\text { artigos científicos; } \\
\text { 3. Correção dos artigos científicos; }\end{array}$ \\
\hline $\begin{array}{l}\text { Insersão na } \\
\text { extensão }\end{array}$ & $\begin{array}{l}\text { 1. Planejamento de atividades educativas nas USF relacionadas a } \\
\text { projetos de pesquisa e extensão*; } \\
\text { 2. Realização de visitas às USF; } \\
\text { 3. Planejamento e realização da palestra "Bioética e Genética" em } \\
\text { instituição sem CEP. } \\
\text { *As atividades educativas planejadas para serem desenvolvidas } \\
\text { nas USF não puderam ser efetivadas no período do Estágio de } \\
\text { Docência. }\end{array}$ \\
\hline
\end{tabular}

Quadro 1: Sinopse do plano e cronograma de atividades desenvolvidas na disciplina Estágio de Docência do Programa de Pós-Graduação em Enfermagem e Saúde da UESB. Jequié/BA, 2009.

Nenhum plano pode ser considerado suficientemente completo ou perfeito de forma que não possa ser alterado no decorrer do processo, até porque algumas 
intercorrências podem vir a acontecer e os envolvidos devem estar atentos e preparados para uma possível alteração nesse plano. Não deve haver rigidez, pois os ajustes serão necessários em algum momento. Ainda assim, o docente deve atentar para os motivos que levaram às mudanças nos planos, se por conta de alguma situação inusitada ou se a metodologia aplicada não foi suficiente para dar conta do conteúdo, a exemplo de discussão de assunto demasiadamente redundante (GIL, 2006).

Em nossa vivência, procuramos elaborar os planos de aula de acordo com os objetivos propostos, o tempo disponível e a metodologia mais adequada (Quadro 1). Para tanto, procuramos utilizar estratégias variadas e motivadoras, algumas delas vivenciadas na disciplina Processo Ensino-Aprendizagem em Ciências da Saúde. Um exemplo disso em nosso planejamento foi a escolha da dinâmica "o urso" para trabalharmos os aspectos éticos em pesquisa. Na dinâmica, os discentes deveriam segurar um urso de pelúcia e fazer com ele o que desejassem naquele momento. Uns abraçavam, outros batiam, outros beijavam... Enfim, faziam de acordo com sua vontade. Ao final da dinâmica, solicitávamos que cada um fizesse com o vizinho da direita o que foi feito por ele no urso. Aí, os que haviam batido no urso ou jogado no chão ou algum outro gesto que pudesse trazer algum constrangimento, não deixavam que o colega fizesse com ele tal gesto. Ou seja, a moral da história era "eu não quero para mim, então, não devo querer para os outros".

Utilizamos esta atividade para tratarmos da Resolução N. ${ }^{\circ}$ 196/1996 do Conselho Nacional de Saúde (CNS), que norteia a realização de pesquisas envolvendo seres humanos. Foi a partir dessa sensibilização que discutimos a temática em pequenos grupos, o que resultou em uma atividade bem sucedida. Essa, dentre outras, foi uma atividade muito enriquecedora e ocorreu exatamente conforme o planejado.

Ministramos também uma aula sobre a elaboração de artigo científico de revisão bibliográfica, na disciplina Metodologia da Pesquisa Científica em Saúde, para a turma do $2^{\circ}$ (segundo) semestre do Curso de Enfermagem. Para iniciar a aula, realizamos a dinâmica "A Palavra Chave", na qual os discentes se organizaram em cinco grupos. Cada grupo recebeu cinco palavras e, dentro de trinta minutos, escolheu uma única palavra e escreveu sobre ela.

Após os trinta minutos, os alunos apresentaram a palavra que escolheram e o que escreveram sobre ela, mas alguns relataram que tiveram dificuldades para entrar em consenso sobre qual palavra escolher e o que escrever sobre ela, pois possuíam opiniões 
diferentes, o que pôde ser observado durante a discussão nos pequenos grupos e também pelo que foi apresentado por eles.

Relacionamos a dinâmica com o assunto a ser ministrado especificando que, na elaboração de um artigo científico de revisão bibliográfica, escolhemos um tema e palavras-chave para realizar nossas buscas nas bases de dados e, muitas vezes, encontramos o mesmo tema com abordagens diferentes. Com isso, lembramos aos discentes que eles estavam elaborando artigos para as disciplinas Deontologia em Enfermagem e Bioética e Metodologia da Pesquisa Científica em Saúde e que esta aula poderia contribuir para o aprimoramento dos trabalhos dos mesmos.

Durante a exposição dialogada, fomos explicando o assunto e esclarecendo, da forma mais simples possível, as dúvidas dos discentes sobre como realizar as pesquisas, quais os itens que um artigo de revisão bibliográfica deve conter, como elaborá-los e qual a importância da utilização de referências. Nossa preocupação era que todos os discentes pudessem compreender o assunto e utilizá-lo como subsídio para elaborar seus próprios artigos. Após a exposição dialogada, realizamos uma atividade, na qual os grupos, previamente formados, recebiam um artigo científico de revisão bibliográfica e deviam identificar suas partes constituintes de acordo com um formulário.

Outra atividade que contribuiu significativamente com a nossa formação para a docência no ensino superior foi a oportunidade de orientar quatro alunas da graduação em Enfermagem na elaboração de seus artigos científicos de revisão bibliográfica para as disciplinas Deontologia em Enfermagem e Bioética e Bioética e Metodologia da Pesquisa Científica em Saúde. Elas trabalharam em duplas e cada dupla foi orientada por uma de nós. Durante as orientações, nós pudemos contribuir para o aprimoramento dos textos, pois indicamos referências e filmes relacionados ao tema, discutimos sobre os assuntos, tiramos dúvidas, trocamos idéias e realizamos correções nos textos. Acreditamos que esta atividade propiciou crescimento profissional para todos os envolvidos: mestrandas, graduandas e os próprios docentes, que revisaram e aprimoraram os artigos científicos gerados com vistas à publicação.

No que concerne às atividades de extensão, realizamos uma palestra em outra instituição de ensino superior da cidade de Jequié, a qual ainda não possui Comitê de Ética em Pesquisa (CEP). A palestra foi realizada a convite do professor da disciplina Genética Humana, ministrada para os discentes do curso de Enfermagem. A palestra, intitulada "Bioética e Genética", teve como objetivo relacionar estas duas temáticas e também apresentar aos discentes o que é o Comitê de Ética em Pesquisa e sua 
importância, bem como suscitar a reflexão dos mesmos para os avanços da Genética, os quais geram dilemas bioéticos.

Em outros momentos, nem tudo aconteceu como planejamos. Pretendíamos, por exemplo, desenvolver ações educativas nas Unidades de Saúde da Família (USF) relacionadas aos projetos de extensão supracitados (drogas, afecções prostáticas e hipertensão arterial). Para tanto, agendamos reunião com as bolsistas dos projetos, planejamos as ações, marcamos reunião com a coordenação municipal da Atenção Básica em Jequié e explicamos todo o projeto e seus objetivos educativos.

Apesar da existência de convênio entre a UESB e a Secretaria Municipal de Saúde de Jequié e de a proposta ter sido muito bem aceita pelo Departamento de Assistência à Saúde do referido órgão, pela enfermeira diretora do departamento e pela assistente social, a implementação das ações foi inviabilizada várias vezes por diversas causas: dificuldades na comunicação, lentidão nos trâmites burocráticos, excesso de atividades existentes sob a responsabilidade das USF, que culminaram com a incompatibilidade do tempo destinado ao semestre letivo. Neste sentido, Mishima et al. (1997) lembram que, embora as universidades tenham buscado maior integração com os serviços de saúde para aproximar a teoria da prática, esta nem sempre é bem sucedida, apresentando limitações, muitas das quais relacionadas ao fato de que estas instituições, universidades e serviços de saúde, desenvolvem processos de trabalho distintos e com finalidades diferenciadas.

Enfim, nossas ações programadas para acontecerem fora da UESB - extramuros - ficaram em sua maioria apenas no plano até meados do mês de outubro, quando finalmente conseguimos realizar algumas visitas nas USF e agendamos as palestras previstas em nosso planejamento. Todavia, entendemos que, para maximizar os resultados, as palestras e as ações educativas deveriam ter sido mais articuladas com os serviços de saúde e sugerimos isso para um próximo momento, pois no momento em que nosso Estágio Docente se desenvolveu não foi possível tal operacionalização. Além disso, a construção/discussão conjunta (universidade, curso de mestrado e Secretaria Municipal de Saúde) da problemática (estratégias para o desenvolvimento de atividades de extensão do mestrado/universidade e superação dos possíveis obstáculos à realização das mesmas) poderia ter sido uma ferramenta significativa nas intervenções a serem implementadas. 


\section{Avaliação das atividades desenvolvidas}

A experiência em Estágio de Docência foi nova para todos que dela participaram e para a própria universidade, uma vez que se trata de mestrandas da primeira turma do Programa de Pós-Graduação em Enfermagem e Saúde. Além disso, esta experiência empregou também inovações como o uso de metodologias alternativas de ensino, a articulação entre ensino e pesquisa e a troca e construção conjunta de conhecimentos, envolvendo discentes de três cursos de graduação distintos, os docentes e as mestrandas.

É importante ressaltar aqui o caráter multi e interdisciplinar deste Programa de Pós-Graduação e dessas atividades relatadas, pois esta turma do referido Programa conta com mestrandos de quatro categorias profissionais: Ciências Biológicas, Enfermagem, Fisioterapia e Odontologia. Tal fato propiciou que as duas mestrandas que vivenciaram essa experiência, uma bióloga e uma enfermeira, pudessem compartilhar e inter-relacionar seus conhecimentos e experiências profissionais na elaboração e desenvolvimento das atividades da disciplina Estágio de Docência, vivência esta que se constituiu para todos os envolvidos como uma significativa experiência multi e interdisciplinar.

Um melhor aproveitamento, talvez, seria a prática das atividades relatadas também em programas como o da Residência Multiprofissional em Saúde; o qual, embora seja uma estratégia de reorientação da Atenção Básica para a implantação/reorganização dos serviços públicos embasados na lógica do Sistema Único de Saúde - SUS (ROSA; LOPES, 2009), ainda não é uma realidade em nossa instituição e em muitas outras instituições do Brasil. Este aspecto pode ser comprovado pelo fato de que, de acordo com Brasil (2006), na Bahia, há apenas 64 (sessenta e quatro) vagas para Residência Multiprofissional, concentradas na capital do Estado, apoiadas pela Secretaria de Gestão do Trabalho e da Educação na Saúde - SGTES, as quais contemplam apenas as seguintes profissões: Enfermagem, Odontologia, Psicologia, Nutrição, Serviço Social, Terapia Educacional, Educação Física, Fonoaudiólogia e Ciências Sociais. Não são contempladas profissões como Ciências Biológicas, Medicina, Fisioterapia, Farmácia, Biomedicina e Medicina Veterinária.

Mesmo assim, não tivemos grandes dificuldades na realização das atividades da disciplina Estágio de Docência, durante as quais estivemos sempre em interação, mestrandas e docentes das disciplinas, no esclarecimento de dúvidas e também para a reserva dos recursos didáticos áudio-visuais utilizados. Os discentes também foram 
receptivos, mantendo respeito e atenção e se mostrando interessados em nossas aulas, questionando e participando ativamente do processo.

Em uma das aulas, tivemos um pequeno problema técnico, próprio da presença da tecnologia em sala de aula. Para finalizar a aula sobre a Resolução N. ${ }^{\circ}$ 196/1996, tínhamos previsto a exibição de dois pequenos vídeos sobre as atrocidades cometidas em pesquisa na Segunda Guerra Mundial (quatro minutos) e sobre o Termo de Consentimento Livre e Esclarecido - TCLE (dois minutos). Todavia estes vídeos só foram exibidos para a turma de Odontologia. Na turma de Enfermagem, esses vídeos foram substituídos pela Mensagem "O Sentido da Vida", pois o notebook, utilizado na aula, não possuía o programa Codex apropriado para rodar os vídeos, mas só percebemos isso no momento da projeção.

Também não foi possível passar os vídeos ou a Mensagem na turma de Medicina, pois a discussão sobre a Resolução N. ${ }^{\circ}$ 196/1996 foi tão intensa e interessante que extrapolamos dez minutos em relação ao horário de término previsto para a aula e o docente da próxima aula já os aguardava.

Outro fator a se considerar é o tempo. Algumas aulas foram desenvolvidas em duas horas e outras em quatro horas. Nas aulas mais longas (quatro horas), foi possível explorar mais as discussões e os questionamentos dos discentes, enquanto nas aulas mais curtas (duas horas), tivemos que reduzir o tempo destinado às discussões e, em uma delas, extrapolamos o tempo previsto pela profícua discussão desencadeada.

Devemos mencionar também que, nos trabalhos em grupos, alguns deles se reuniram na própria sala de aula, mas outros preferiram se reunir em salas que estavam vazias, argumentando que assim poderiam ter mais concentração e não seriam incomodados pelos outros grupos. Tal solicitação nos causou uma preocupação momentânea, pois temíamos a dispersão destes grupos que iriam trabalhar em outras salas. Mesmo assim, preferimos permitir que eles se reunissem mais livremente e demos esse voto de confiança. Embora tal solicitação tenha dificultado que acompanhássemos o andamento dos trabalhos em todos os grupos da mesma forma, pois tínhamos que procurar a sala e não podíamos vê-los trabalhando durante todo o tempo, notamos nas discussões, que eles executaram as tarefas solicitadas e, na maioria das vezes, superaram nossas expectativas na discussão do assunto.

Devemos assinalar também que as turmas são diferentes entre si. As turmas de Enfermagem e Odontologia eram mais jovens, mas eram diferentes no que concerne aos gêneros; uma vez que na turma de Enfermagem as mulheres predominavam, enquanto 
na de Odontologia o predomínio era masculino. Tais aspectos podem ser explicados pelo fato de que, historicamente, a Enfermagem tem sido considerada uma profissão mais destinada às mulheres (PELÁ; GALANTE; GABRIELLI, 2002), enquanto a Odontologia era considerada uma profissão tipicamente masculina (COSTA; DURÃES; ABREU, 2010).

A turma de Medicina é mista (não há uma grande diferença entre os gêneros). De acordo com Begliomini (2006), esta profissão também é tradicionalmente masculina; mas, nos últimos anos, tem ocorrido um incremento no número de mulheres médicas. Aparentemente, esta turma possui uma faixa etária mais elevada, o que pode ser comprovado pelo fato de que muitos discentes, durante a apresentação, revelaram já possuir um curso superior ou terem abandonado o curso que faziam antes de ingressar em Medicina. Além disso, pudemos notar que todos eles são de outras cidades e alguns até de outros estados do Brasil.

Estas diferenças podem influenciar no comportamento das turmas, uma vez que a turma de Odontologia é mais inquieta e efusiva, enquanto a de Enfermagem é mais reflexiva e a de Medicina destaca-se pela habilidade em relacionar vivências anteriores às discussões e à elaboração de questionamentos, demonstrando mais amadurecimento. Tais diferenças nos permitiram entender também essa fase do processo ensinoaprendizagem, respeitando as diferenças individuais e coletivas.

Apesar das diferenças, queremos reforçar que todas as turmas se envolveram significativamente nas aulas e se empenharam nas atividades propostas, respeitando o nosso momento de prática docente, de tal modo que nos deixaram surpresas e lisonjeadas com o empenho e o interesse de todos.

No que concerne à palestra realizada para discentes do curso de Enfermagem de outra instituição de ensino superior, notamos que os discentes a assistiram com atenção e se mostraram interessados pela temática "Bioética e Genética" e, notadamente, sobre o Comitê de Ética em Pesquisa (CEP); uma vez que boa parte das perguntas que fizeram após a palestra era sobre o CEP. Contudo, percebemos que muitos deles ficaram um pouco tímidos por não terem tido uma abordagem anterior sobre o CEP, pois a região Sudoeste da Bahia (na qual está situada a cidade de Jequié) possui apenas um CEP, o CEP/UESB e nem todos os cursos de graduação possuem em seu currículo a disciplina Bioética. Apesar disso, acreditamos que a palestra cumpriu seu papel ao estimulá-los a refletir sobre a relação existente entre a Bioética e a Genética e sobre a importância do CEP, sendo significativo também para o próprio CEP da UESB, uma vez que o CEP 
também deve exercer a função educativa e que uma das autoras deste trabalho, além de mestranda, é também a secretária do CEP/UESB.

\section{Considerações finais}

A execução de cada uma das nossas atribuições enquanto estagiárias/mestrandas/docentes proporcionou-nos uma oportunidade de inter-relação que foi além de conteúdos e planos. Excedeu inclusive a nossa própria expectativa, uma vez que tivemos que lançar mão de ferramentas adequadas ao exercício da docência, as quais nos instrumentalizaram para lidar com os desafios que surgiram e que, certamente, permeiam o processo ensino-aprendizagem percebido pelos que já estão na docência e também pelos que pretendem ingressar nela.

Executar tais atividades para nós significou uma oportunidade excelente de crescimento e troca de saberes e experiências, tendo em vista a possibilidade de relacionamento com docentes, bolsistas, discentes, colegas, departamentos e instituições, favorecendo o nosso amadurecimento enquanto mestrandas/estagiárias e futuras profissionais/mestres da área de Saúde Pública, área de concentração do Programa de Pós-Graduação em Enfermagem e Saúde.

Assim, nós pudemos perceber que a docência, além de ser uma profissão extremamente relevante em todos os aspectos (educacionais, biopsicosociais, econômicos e políticos), envolve o ensinar e o aprender, como algo intrínseco ao ser humano, acontecendo em todas as etapas da vida e em todos ambientes, já que acreditamos que este processo inicia-se ainda no útero, quando começamos a reconhecer as vozes e os estímulos fornecidos a nós por nossos pais.

Apesar destes fatos que, em nossa opinião, nos mostram que ensinar e aprender não são processos estanques, e sim contínuos, e de nossa experiência ter sido, a nosso ver, exitosa, pudemos notar também que não são processos tão simples e fáceis como podem aparentar à primeira vista, pois eles são entremeados de fatores que podem influenciá-los positiva e/ou negativamente, tais como a existência ou não de recursos didáticos, o tipo de metodologia utilizada, o ambiente no qual são realizadas as aulas, o estabelecimento de relações entre os conteúdos ministrados e o cotidiano dos discentes, o interesse dos envolvidos no processo (docentes, mestrandas e discentes), dentre outros aspectos. 
Em nossa experiência na disciplina Estágio de Docência, contamos com os recursos que desejávamos, empregamos diferentes metodologias de ensinoaprendizagem, procuramos estabelecer relações entre os conteúdos ministrados e o cotidiano dos discentes através de questionamentos e situações problemas e nos empenhamos para que a experiência do ensino-aprendizagem que estávamos compartilhando com os discentes fosse tão prazerosa para eles quanto para nós.

\section{Referências}

BEGLIOMINI, Hélio. Analise ética dos urologistas no estado de São Paulo. Rev. Para. Med. V. 20, n.2, p.29-33, jun., 2006.

BRASIL. Ministério da Saúde. Secretaria de Gestão do Trabalho e da Educação na Saúde. Departamento de Gestão da Educação na Saúde. Residência multiprofissional em saúde: experiências, avanços e desafios. Ministério da Saúde, Secretaria de Gestão do Trabalho e da Educação na Saúde, Departamento de Gestão da Educação em Saúde. - Brasília: Ministério da Saúde, 2006.

COSTA, Simone de Melo; DURÃES, Sarah Jane Alves; ABREU, Mauro Henrique Nogueira Guimarães de. Feminização do Curso de Odontologia da Universidade Estadual de Montes Claros - UNIMONTES/ Brasil. Ciência \& Saúde Coletiva. V. 15, suppl.1, p.1865-1873, jun. 2010.

GIL, Antônio Carlos. Didática do Ensino Superior. São Paulo: Ática, 2006.

LOPES, Antônia Osima. Relação de Interdependência entre ensino e aprendizagem. In: VEIGA, Ilma Passos Alencastro. Didática: o ensino e suas relações. 6 ed. São Paulo. Papirus, 1996. p. 105-114

MARTINS, Antônio Carlos Pereira. Ensino superior no Brasil: da descoberta aos dias atuais. Acta Cir. Bras. V. 17, suppl. 3, p. 04 - 06, 2002.

MISHIMA, Silvana Martins et al. A relação universidade e serviços de saúde construindo possibilidades de trabalho. Rev.latino-am.enfermagem. V. 5, n. 2, p. 17-22, abr., 1997.

MIZUKAMI, Maria da Graça Nicoletti. Ensino: as abordagens do processo. São Paulo. E.P.U., 1986.

PELÁ, Nilza Teresa Rotter; GALANTE, Anderson Cleyton; GABRIELLI, Joyce M. Worschech. Aluno (homem) de enfermagem: seu significado para universitários. In: Anais do Simpósio Brasileiro de Comunicação em Enfermagem. N. 8, mai., 2002. Disponível em: <http://www.proceedings.scielo.br/scielo.php?script=sci_arttext\&pid=MSC0000000052 002000100004\&lng=en\&nrm=abn> . Acesso em: 25 Out. 2009. 
ROSA, Soraya Diniz; LOPES, Roseli Esquerdo. Residência multiprofissional em saúde e pós-graduação lato sensu no Brasil: apontamentos históricos. Trab. Educ. Saúde. V. 7 n. 3, p. 479-498, nov., 2009.

SEVERINO, Antônio Joaquim. O ensino superior brasileiro: novas configurações e velhos desafios. Educ. rev.. Curitiba, n. 31, p. 73-89, 2008.

SILVA, Alberto Carvalho da. Alguns problemas do nosso ensino superior. Estud. av. V.15, n. 42, p. 269-293, mai./ago., 2001. 